SAND-79-0939

UNLIMITED DISTRJBUTION

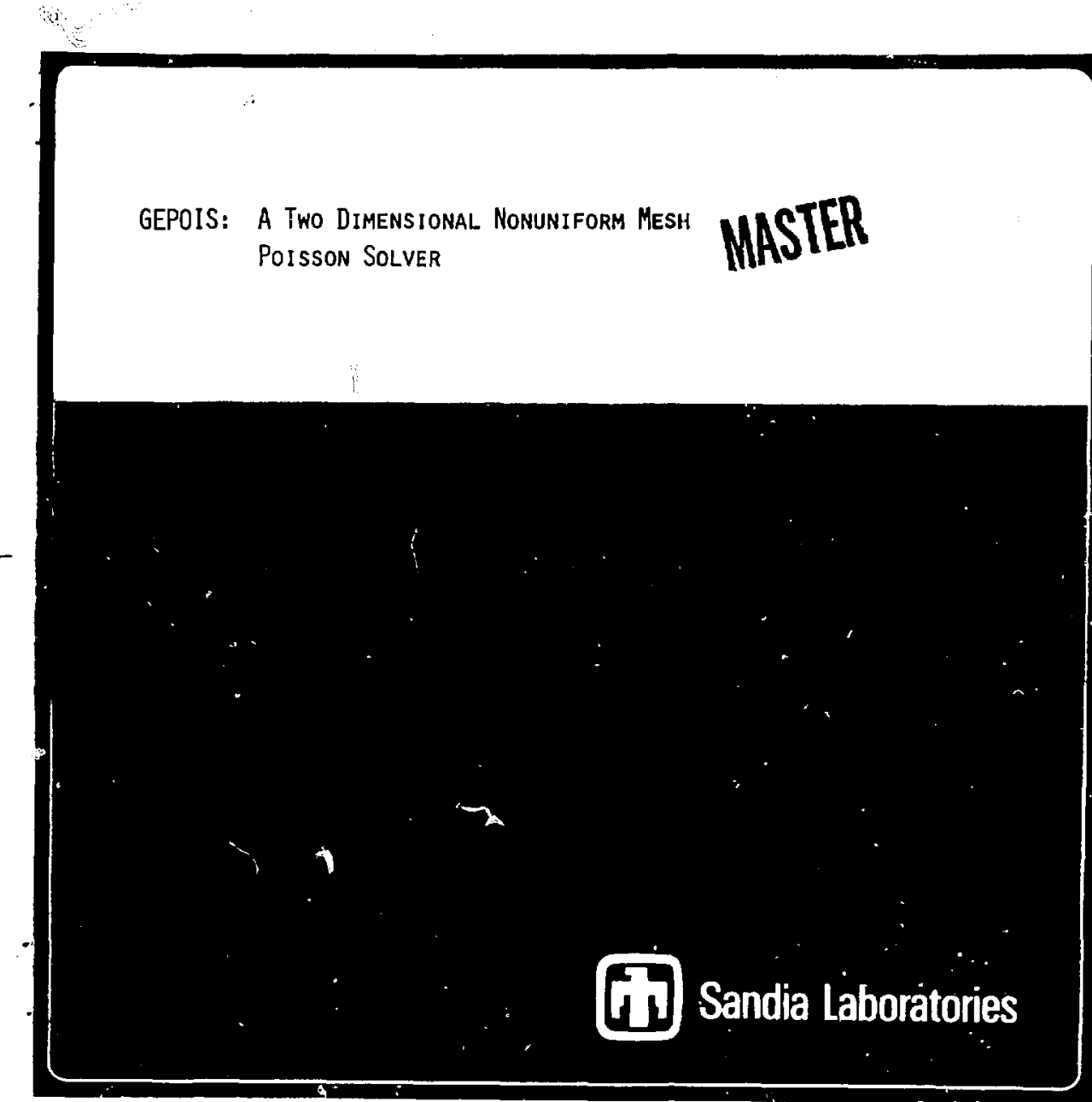




\title{
GEPOIS: A Two Dimensional Honuniform Mesh Poisson Solver
}

\author{
J. P. Quintenz and J. R. Freeman \\ Division 4241 \\ Sandia Laboratories \\ Albuquerque, New Mexico
}

June 1979

\begin{abstract}
This report describes a computer code which solves Poisson's equation for the electric potential over a two dimensional cylindrical $(r, z)$ nonuniform mesh which can contain internal electrodes. poisson's equation is solved over a given region subject to a specified charge distribution with either Neumann or Dirichlet perimeter boundary conditions and with Dirichlet boundary conditions on internal surfaces. The static electric field is also computed over the region with special care given to normal electric field components at boundary surfaces.
\end{abstract}

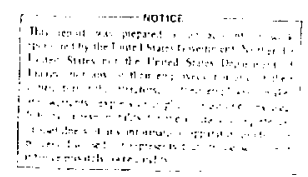




\section{ITABLE OF CONTEHTS}

Page

A. Introdlction . . . . . . . . . . . . . . . 5

6. Gethod of Solution. . . . . . . . . . . . . . 5

c. Gode Description................. I6

Appendix I: Summary of Input Parameters and

Dimensioninf. . . . . . . . . . . . . . 29

A. Dimenstoring. . . . . . . . . . . . . 29

5. Calling Parameters . . . . . . . . . . . 29

C. Common Block................. 30

Appondix II: Input for Sample Problem . . . . . . . . 33

Appendix III: Code Listing. . . . . . . . . . . . . 35

References................... 46 


\section{A. Intioduction}

Particle-in-cell (PIC) simulation codes have been used Eor several year: $1-5$ to investigate the behavior of intense particle beams in diodes. These simulations have helped to explain the results of experiments which have been performed in the development and application of drivers for intense particle beam inertial confinement fusion research. A flow chart of a typical steady state diode code is shown in figure 1 . As can be seen from the fluw chart, the steps involved in obtaining a self-consistent steady state solution for the current and charge distribution in a dlode simulation are as follows: First the electric potential is found for a particular charge distributior, and diode configuration. The electric field which results from this electric potential, together with the charge density is then used to determine how much charge should be emitted at that time step assuming space charge Iimited emission from all emitting surfaces. Simulation particles are introduced at these emission surfaces with charge corresponding to that specified by the emission law. These simulation particles are then pushed in the electric and magnetic fields one time step. New values of charge and current density are computed from the new simblation particle positions and velocities. The current density is integrated to produce the magnetic field component $B_{\theta}$. Poisson's equation is then solved for the new charge distribution and the process is then repeatied until a steady state is reached. The result is a description of the particle 


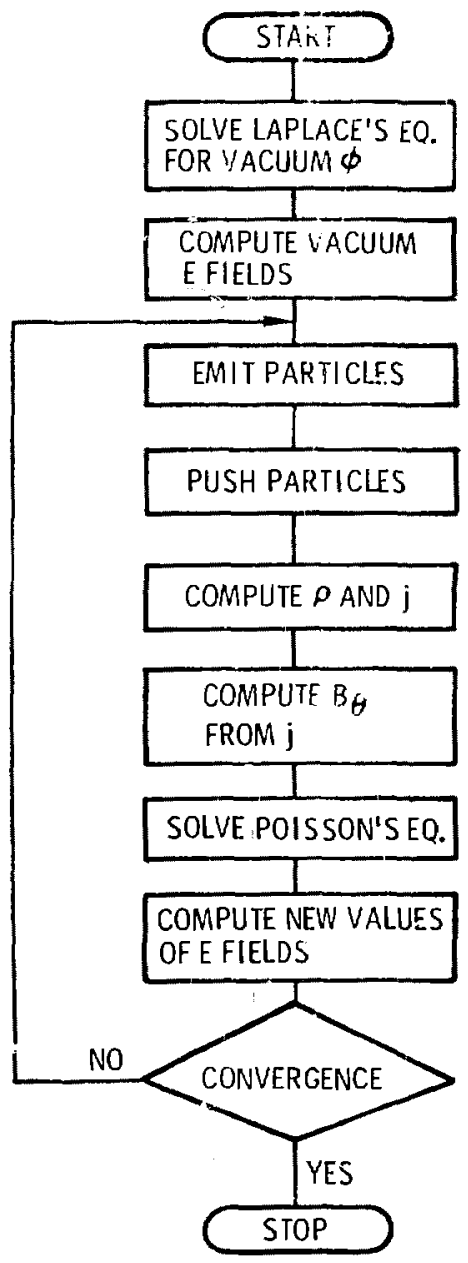

Figure 1. Diode Simulation FIC Code Flow Chart. 
bean behavior in its own self-consistent fields.

Solving Poisson's equation and obtaining the electric fields. in the dione are integral parts of the above process. This report is a description of the latest version of the poisson solver in the Sandia riode code. The earliest versions of the diode code ${ }^{I}$ used a solver incorporating a fast fourier transform (FFT) in the 7 dicection and cyclic reduction in $r$. The pri restricted the zoning of the finite difference mesh to be uniform in 7 and also required that the number of mesh 1 ines in $z$ be equal to an integer power of 2. A capacity inatrix was necrer to treat internal electrode points. This solver was extrenely fast, rut as iliode configurations becane more complex the need for nonuniform zoning in both the $r$ and $z$ directions became apparent. Although the new solver, which is based on an alternating-direction-implicit iteration method, is somewhat slower than the previous one, the added flexibility of internal sulface description and spatial detail more than offset the increased run time.

Section B describes the metioci of solution of Poisson's equation and the computation of the electric field components. Section $C$ describes the code in detail including pertinent inputs, dimensions, etc. There are three appendices to help the usex. In Appendix I a summary of required inputs and dimensioning is presented in tabular form. Appendix II contains the input required for a sample problem which is discussed in the text. Finally, a complete listing of the code is given in Appendix III. 


\section{B. Method : Solution}

In GEPOIS the first step in solving for the electric potential in a region is the definition of a finite difference mesh or grid. Figure 2 shows the $h, m$ grid point with its surrounding mosh zones and grid points on a nonuniform mesh. In this Eiglure, terms are defined which will be used in the following description of the method.

$$
\text { Poisson's equation in cylindrical coordinates for an }
$$
axisymetric system is

$$
\nabla^{2} \phi=\frac{\partial^{2} \phi}{\partial x^{2}}+\frac{1}{r} \frac{\partial \phi}{\partial r}+\frac{\partial^{2} \phi}{\partial z^{2}}=-\rho / \epsilon
$$

To solve this equation by finite difference techniques, approximations to the first and scoond derivatives on a nonuniform mesh are needed. These are obtained from a Taylor series expansion of the function, viz:

$$
E(x)=F^{\prime}\left(x_{0}\right)+\left(x-x_{0}\right) f^{\prime}\left(x_{0}\right)+\frac{\left(x-x_{0}\right)^{2} f^{\prime \prime}\left(x_{0}\right)}{2}+\ldots
$$

$$
\begin{aligned}
\text { Now if } \mathrm{x} & =\mathrm{x}_{0}+\Delta_{+} \\
\mathrm{f}_{+} & =\mathrm{E}_{\mathrm{O}}+\Delta_{+} \mathrm{f}^{\prime}\left(\mathrm{x}_{\mathrm{O}}\right)+\frac{\Delta_{+}{ }^{2} \mathrm{f}^{\prime \prime}\left(\mathrm{x}_{\mathrm{o}}\right)}{2}+\ldots
\end{aligned}
$$




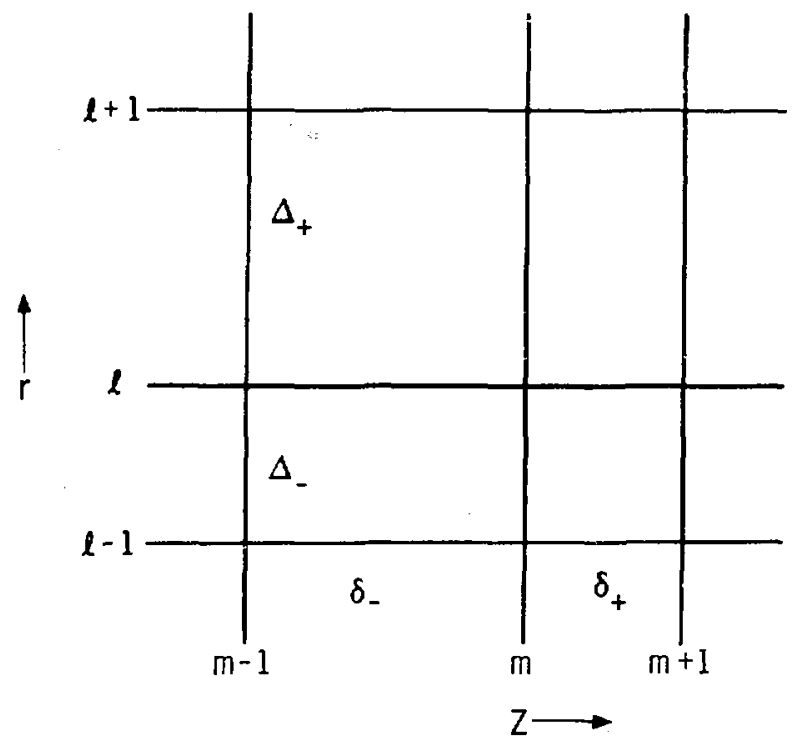

Figure 2. Grid Section Defining Terms. 


$$
\begin{aligned}
& \text { or if } x=x_{0}-\Delta_{-} \\
& f_{-}=f_{O}-A_{-} f^{\prime}\left(x_{0}\right)+\frac{\left.s^{2}{ }^{2} "{ }^{\prime} x_{0}\right)}{2}+\ldots
\end{aligned}
$$

where the notation

$$
\begin{aligned}
& r_{+}=f\left(x_{0}+s_{+}\right) \\
& f_{0}=f\left(x_{0}\right) \\
& r_{-}=E\left(x_{0}-\Delta_{-}\right)
\end{aligned}
$$

has been used. Equations (3) and (4) can be solved simultaneously [or the Eirst and second derivatives of the function at $x_{0}$ in terms of the function values at $x_{0}, x_{0}-\Delta_{-}$, and $x_{0}+\Delta_{+}$. The results are

$$
\begin{aligned}
& E^{\prime}\left(x_{0}\right)=\frac{\Delta_{+}^{2}\left(f_{0}-f_{-}\right)+\Delta_{-}^{2}\left(f_{+}-f_{0}\right)}{\Delta_{+} \Delta_{-}\left(\Delta_{+}+\Delta_{-}\right)}+O\left(\Delta_{+} \Delta_{-}\right) \\
& f^{\prime \prime}\left(x_{0}\right)=\frac{2 \Delta_{+}\left(f_{-}-f_{0}\right)+2 \Lambda_{-}\left(f_{+}-f_{0}\right)}{\Delta_{+} \Delta_{-}\left(\Delta_{+}+\Delta_{-}\right)}+O\left(\Delta_{+}-\Delta_{-}\right)
\end{aligned}
$$

Kalnay De Rivas ${ }^{6}$ has shown that if the grid intervals are varied using a stretched coordinate $x=x(\xi)$ in such a way as to insure that the $\Delta \xi$ are constant, $\frac{d x}{d \bar{\xi}}$ is finite over the interval and $\frac{d x}{d \xi}$ is zero only where high resolution is desired, then equations (5) and (6) will give approximations to the first and second derivat<ves which are accurate to second order in the mesh spacing.

Using the notation of Figure 2 and the results of (5) and (6) a finite difference approximation for Poisson's 


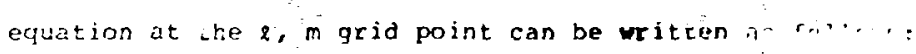

$$
\begin{aligned}
& A_{l} l_{l+1, m}+b_{l} \phi_{l, l}+c_{l} \phi_{l-1, m}+D_{m} p_{2, m+1} \\
& =+\underbrace{\phi_{2}, m}_{n}+F_{m} \phi_{2, m-1}=G_{2, m}
\end{aligned}
$$

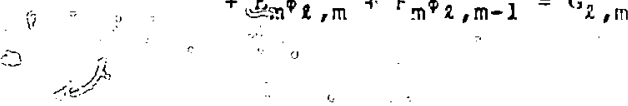

where

$$
\begin{aligned}
& s_{\ell}=\left(2 A_{-}+A_{-}^{2} / r_{\ell}\right) \alpha \\
& B_{\ell}=-\left\lfloor A_{\ell}+C_{\ell}\right] \\
& C_{\ell}=\left(2 \Delta_{+}-\Delta_{+}^{2} / r_{l}\right) a \\
& D_{m}=2 \delta \_B \\
& E_{m}=-\left[D_{m}+F_{m}\right] \\
& F_{\text {TR }}=2 \delta_{+}^{B} \\
& \mathrm{G}_{2, \mathrm{~m}}=\mathrm{o}_{2, \mathrm{~m}^{\prime} \epsilon} \\
& \alpha=\frac{1}{\Delta_{+} \delta_{-}\left(\Delta_{+}+\Delta_{-}\right)}, B=\frac{1}{\delta_{+} \delta_{-}\left(\delta_{+}+\delta_{-}\right)} .
\end{aligned}
$$

Eúuation (7) is solved using an alternatirg-direction-implicit (ADI) method with a Wachspress iteration parameter sequence ${ }^{7}$, viz:

$$
\begin{aligned}
& A_{\ell} \star_{\ell+1, m}+\left(B_{\ell}-n^{k}\right)_{\psi^{*}{ }_{\ell, m}}+C_{Q^{\phi^{*}}{ }_{\ell-1, m}} \\
& =G_{\ell, m}-D_{m} \phi_{l, m+1}^{0}-\left(E_{m}+n^{k}\right) \phi_{l, m}^{0}-E_{m} \phi_{l, m-1}^{0}
\end{aligned}
$$

where $^{8}$ 


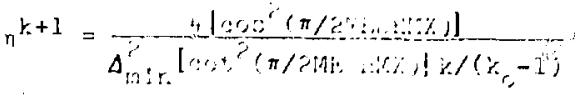

$$
\begin{aligned}
& k=0, i, \ldots, k_{0}-1 \text {. }
\end{aligned}
$$

In E. (9). MEsHMx is the maximum number of zones in either

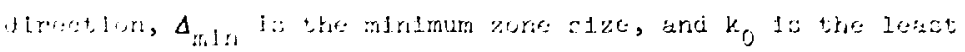

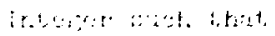

$$
k_{0}-1+\frac{\ln \{\tan [(\pi / 2 M \operatorname{EShM} x)]\}}{\ln (\sqrt{2}-1)}
$$

On successive passes in the iterative solution of Eq. (8), the right-hand side of the equation is assumed to be known using previous values of potentials, and the starred values of potential are then found using a two-pass direct iuthod. Wext, new values of potential are found by solving

$$
D_{m i}^{\phi_{\ell, m+1}^{n}}+\left(E_{m}-n^{k}\right) \phi_{\ell, I n}^{n}+F_{m}^{\phi} n_{\ell, m-1}^{n}=H_{\ell, m}^{*} \text {, }
$$

where

$$
\begin{aligned}
H^{\star}{ }_{\ell, m}= & G_{\ell, m}-A_{\ell} \phi^{\star}{ }_{\ell+1, m} \\
& -\left(B_{\ell}+n^{k}\right)_{\phi^{\star}{ }_{\ell, m}}-C_{\ell} \phi^{\star} \ell-1, m
\end{aligned}
$$

with the same two-pass direct methcs: After each complete iteration, $k$ is incremented by one until $k=k_{0}$, at which time $k$ is set back to zero and the sequence begins again. The two-pass direct method of solution is outlined below. It is desired to solve the equation

$$
A_{j} \phi_{j+1}+\left(B_{j}-n^{k}\right) \phi_{j}+C_{j} \phi_{j-1}=H_{j}
$$


where $j$ is either \& or $m$ and $A_{j}$ is either $A_{\ell}$ ir $D_{m}$, etc. Suppose

$$
\cdot c_{j}=o_{j} \phi_{j-1}+P_{j}
$$

Then

$$
\phi_{j+1}=o_{j+1} \phi_{j}+P_{j+1}
$$

Substituting (12) into (10) yields

$$
\begin{aligned}
& \qquad A_{j}\left[O_{j+1} O_{j}+P_{j+1}\right]+\left[B_{j}-n^{k}\right] \beta_{j}+C_{j} \phi_{j-1}=H_{j} \\
& \text { or } O_{j}\left[A_{j} O_{j+1}+B_{j}-\eta^{k}\right]+C_{j} \phi_{j-1}=H_{j}-P_{j+1} A_{j} \\
& \text { but } C_{j}-O_{j}{ }_{j-1}=P_{j} \\
& \text { so that }
\end{aligned}
$$

$$
\begin{aligned}
& \therefore_{j}=\frac{C_{j}}{A_{j}{ }_{j+1}+B_{j}-n_{i}^{k}} \\
& P_{j}=\frac{!_{j}-A_{j} P_{j+1}}{A_{j} O_{j+1}+B_{j}-n^{k}}
\end{aligned}
$$

Note that if $O_{j+1}$ and $P_{j+1}$ are known then $O_{j}$ and $P_{j}$ are determined by (13) and (14). Also, if all $O_{j}$ and $P_{j}$ are known then all $\phi_{j}$ are specified by (11). The first pass of the two pass direct method bejins at the uppermost $j$ bunfary where two possible conditions exist; either $\phi_{j}$ max is specified or $\frac{\partial \phi}{\partial n}=0$ there. If $\phi_{j} \max$ is specified then from (II)

$$
o_{j \max }=0 \quad \text { and } \quad e_{j \max }=\phi_{j \text { nax }}
$$


and (13) and (14) can be applied er:asivaly until all $O_{j}$ and $P_{j}$ through $O_{j} m i n$ anc $p_{j}$ in $m$ are determined. If $\frac{\partial \psi}{\partial n}=0$ at the upper boundary then further anaiysis is required. Equation (5) can be solred for $\phi_{j+1}$ when $\frac{\partial \dot{\rho}}{\partial n}=0$ to yield

$$
p_{j+1}=\left|p_{j-1}-\hat{k}_{j}\right|\left[\begin{array}{l}
\Lambda_{+} \\
\Lambda_{-}
\end{array}\right]^{2}+\epsilon_{j}
$$

Substituting this relation into (10) and arain solving for $O_{j} \max$ and $P_{j} \max$ gives

$$
\begin{aligned}
& O_{j \max }=\frac{-\left\lfloor A_{j \max }\left(\frac{\Delta_{+}}{\Delta_{-}}\right)^{2}+c_{j \max }\right]}{\left[D_{j \max }-n^{k}+A_{j \max }\left(1-\left(\frac{i^{+}}{L^{-}}\right)^{2}\right]\right.} \\
& P_{j \max }=\frac{H_{j \max }}{\left[B_{j \max }-n^{k}+\Lambda_{j \max }\left(1-\left(\frac{\Delta^{j}}{\Delta^{-}}\right)^{2}\right]\right.}
\end{aligned}
$$

Again, (13) and (14) can be applied recursively until $O_{j} \mathrm{~min}$ and $P_{j}$ min are determined. To cstain the potential $\phi_{j}$ for all $j$ the second pass of the two-pass direct method begins at the lower boundary. If $\dot{\phi}_{j} \min$ is specified, then all remaining $\phi_{j}$ are obtained from (12) by recursion. If, however, $\frac{\partial \phi}{\partial n}=0$ on the lower boundary, ther again further analysis is required. Equation (15) is now substituted into (11) and (12) with the result that

$$
\phi_{j \min }=\frac{o_{j \min } P_{j \min +1}\left(\frac{\Delta^{-}}{\Delta^{+}}\right)^{2}+P_{j \min }}{1-o_{j \min }\left[\left(o_{j \min +1}-1\right)\left(\frac{\Delta^{-}}{\Delta^{+}}\right)^{2}+1\right]}
$$


Equation (26) is valid for a homogeneous Neumann bisundary condition on a lower boundary except when the boundary is the $z$ axis $(r=0)$. In this case the $\frac{l}{r} \frac{\partial \phi}{\partial r}$ term in Poisson's equation becomes indeterminant and must be removed using L'Hospital's rule. In actuality (13), (14) and (16) are still correct in this case but the expressions for $A_{\dot{z}}$ and $c_{2}$ below (7) become

$$
\begin{aligned}
& A_{\ell \text { ain }}=\frac{\Delta \Delta_{-}}{\left(\Delta_{+}+\Delta_{-}\right) \Delta_{+} \Delta_{-}}=\frac{2}{\Delta_{+}^{2}} \\
& C_{\ell \text { min }}=\frac{4 \Delta_{+}}{\left(\Delta_{+}+\frac{\Delta_{-}}{\Delta_{-}}\right)}=\frac{2}{\Delta_{+} \Delta_{-}}
\end{aligned}
$$

Here $\Delta_{-}$is set equal to $\Delta_{+}$on all exterior boundaries. The two-pass method as described above is used on each successive row or column of the difference mesh until all values of $\phi_{\ell, m}$ or $\zeta_{\ell, m}^{*}$ are determined.

The ADI procedure is repeated until converger.e is reached. The convergence criterion may be adjusted by the user to the required accuracy. The criterion used in

GFPOIS is that

$$
\left.\sum_{\text {mesh }}(1)-N\right)^{2} / \sum_{\text {mesh }}(N)^{2} \leqslant \operatorname{conv}
$$

where $O$ and $N$ refer to $o l d$ and new values of $\phi_{\ell}, m$ respectively. Here conv is typically $\sim 10^{-13}-10^{-17}$.

With the potential computed, the electric field is calculated by using $E=-\nabla \phi$. This implies that 


$$
\begin{aligned}
& E_{r}=-\frac{\partial \phi}{\partial r}, \\
& E_{z}=-\frac{\partial \phi}{\partial z} .
\end{aligned}
$$

The derivatives above are computed using the approximation given in Eg. (5). On boundarles, the normal clectric field component is camputed using a guadratic fit to the potential and differentiating this quadratic function. This avoids the one sided difference and its inherent inaccuracy. An additional advantage of the ADI method is its generality when compared with dirst: solvers. Many other elliptic equations can be treated by this technigue. ${ }^{7}$

\section{Code Description}

Subroutine GEPOIS, together with its companion routine GENSLV, computes the electric potontial over a specified 2-d, nonuniform, cylindrical $(r, z)$ mesh, subject to a known charge distribution and rather general boundary conditions. The $r$ and $z$ components of the electric field san alro be obtained by setting the appropriate flag when calling GEPOis. The pataneter list for calling GEPOIS is

CALL GEPOIS (ISET, IEF, IMX, CONV, NR, NZ, R, Z, INELPT, PHI, ER, RHOEZ, DUMABC, DUMAOP, DUMERC， DUMEZC， DUMDR, DUMDZ)

Each parameter will be explained below.

\section{1) INPUT}

a) ISET. The first call to GEPOIS sets constants. ISET must be equal to 1 during this first 
call. ISET must not equal 1 during subsequent calls to GEPOIS. The first call to GEPoIs is a dummy call and does not conpute potentials.

b) IEF. This is a flag which when 1 results in the computation of both potential and electric field. If IEF is not equal to 1 only the potential is comuuted.

c) IMX. The maximum number of iterations to try in the ADI process before stopuirg and printing a convergence failure message.

d) Conv. The convergence criteria as defined in (17).

e) NR The array size in the r airection. NR is equal to the number of $r$ grid lines plus 2.*

f) Nㅡ. The array size in the $z$ direction. NZ is equal to the number of $\mathrm{z}$ grid 1 ines plus 2. *

5) R. The array containing the $r_{l}$ values of the grid 1 ines. *

h) 2 . Array containing the $z_{m}$ values of the grid 1 ines.*

i) INELPT, Array specifying which grid points are to be held at fixed potentials. If INELPT $(L, M)$ equals 1 then the L, M grid point is held fixed at $\operatorname{PHI}(\mathrm{L}, \mathrm{M})$ volts. If $\operatorname{INELLT}(\mathrm{L}, \mathrm{M})$ equals o then the L,M grid point potential will be computed.*

* (See grid description below) 


\section{2) INPUT/OUTPUT}

a) PHI. The array which contains the value of potential at each grid point. PHI $(L, M)$ must be set on all Dirichlet boundaries and at all points where $\operatorname{INELPT}(L, M)=1$ prior to the call to GEPOIS.

b) RHOE2. The array which contains the value of $-o / \varepsilon$ at each grid point before the GePors call and which contains the value of. $\mathrm{E}_{Z}$ (when $\mathrm{IEF}=1$ ) at each grid poinc after the GEPOIs call.

\section{3) OUTPUT}

a) ER. The array which contains the value of $\mathrm{E}_{\mathrm{r}}$ (when IEF = 1) after the call to GtPoIs.

\section{4) DUMMY VARIABLES}

a)

Al - Farameters with names starting with DUM are only dimensioned in the main program. This provites storage locations for constants defined in GEPOIS and makes subrouines useable withort themselves having to be redimensioned with each new problem.

In addition to the above calling parameters, the user must define a common block in the calling program as

COMMON/SURF/IDS $(4,4,5), \operatorname{NOS}(4), \operatorname{NOSS}, \operatorname{IBC}(4)$

Each of these variables relate to surface description and boundary conditions. 'l'hey are explained in tire mesh and surface description below. 
The first consideration in using these routines is the definition of a differencing mesh. Figure 3 details a sample problem which will be used to describe the code features in all that follows. Figure 4 show: a nonuriform mesh which has been chosen to solve this problem. The $r$ direction index is $\ell$ and the $z$ direction index is $\mathrm{m}$. The mesh is defined froirl $l$ to $N R$ in $r$ and $l$ to $N Z$ in $z$. The actuil problem boundaries are 2 to NR-1 and $z$ to NZ-1 allowing for one extra zone around the entire mesh, a feature which is not used in this code but has applicatiors in particle-in-cell codes. The $(r, z)$ location of the grid lines must be specified by defining $R(L)$ and $Z(M)$ arrays in the calling program. Care should be taken in choosing these grid lines to insure accuracy in the final potential solution. (Refer to Kalnay De Rivas ${ }^{6}$ for guidance in choosing acceptable variations in grid spacings.) In the sample problem $\Delta r$ increases from botton to top by the power 1.15 and $\Delta z$ increases from right to left by the power 1.20 . The reader can verify that this choice of zoning does satisfy the restrictions to insure the desired accuracy in the Poisson solver. ${ }^{6}$

In the sample problem of Figure 3 there are internal surfaces shown. (Note: Internal surfaces are any surfaces which fall inside the region Jefined by the mesh. The four boundaries of the region, top, bottom, right and left are refirred to here as perimeter surfaces or boundaries. An 


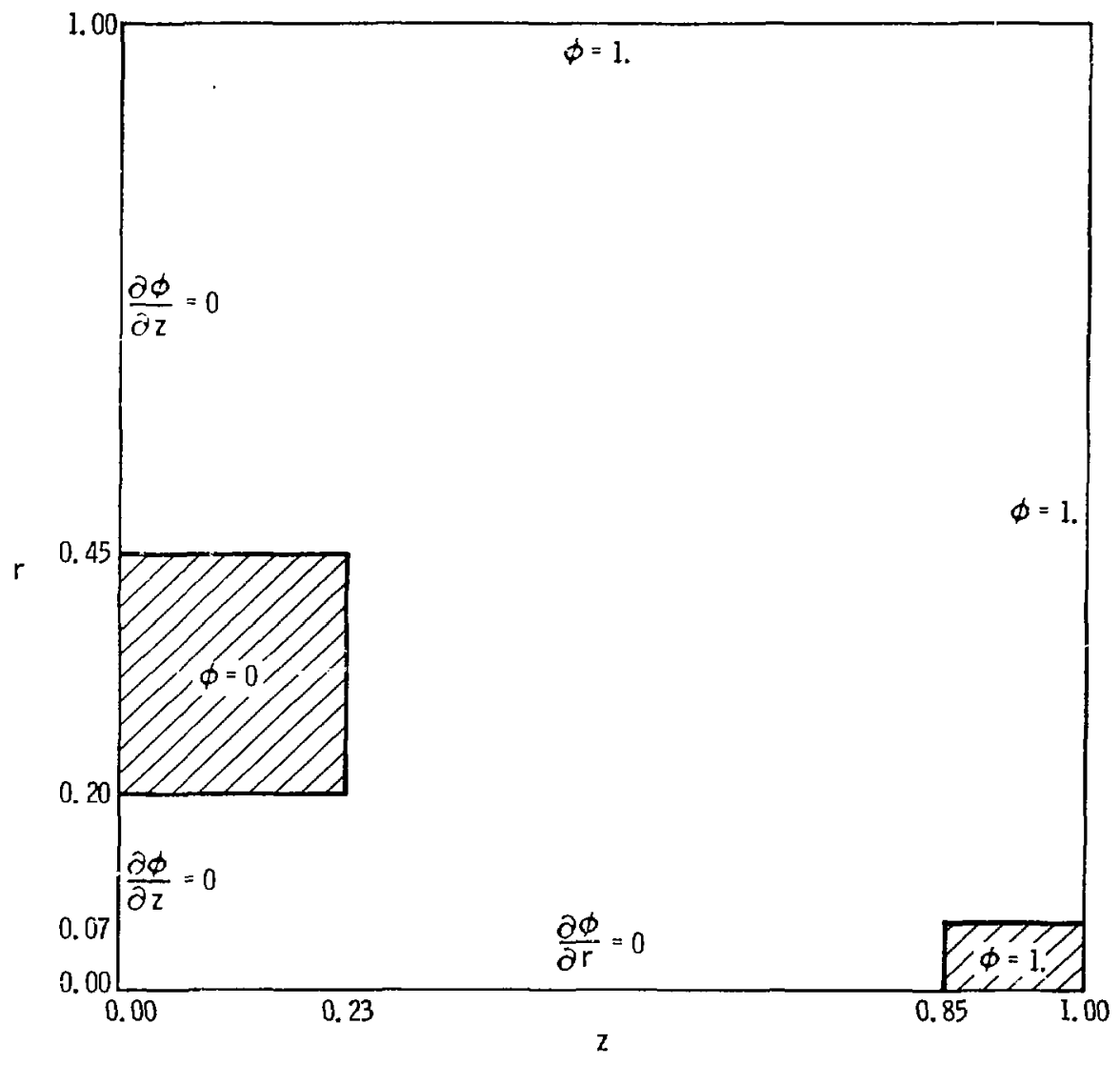

Figure 3. Sample Problem. 


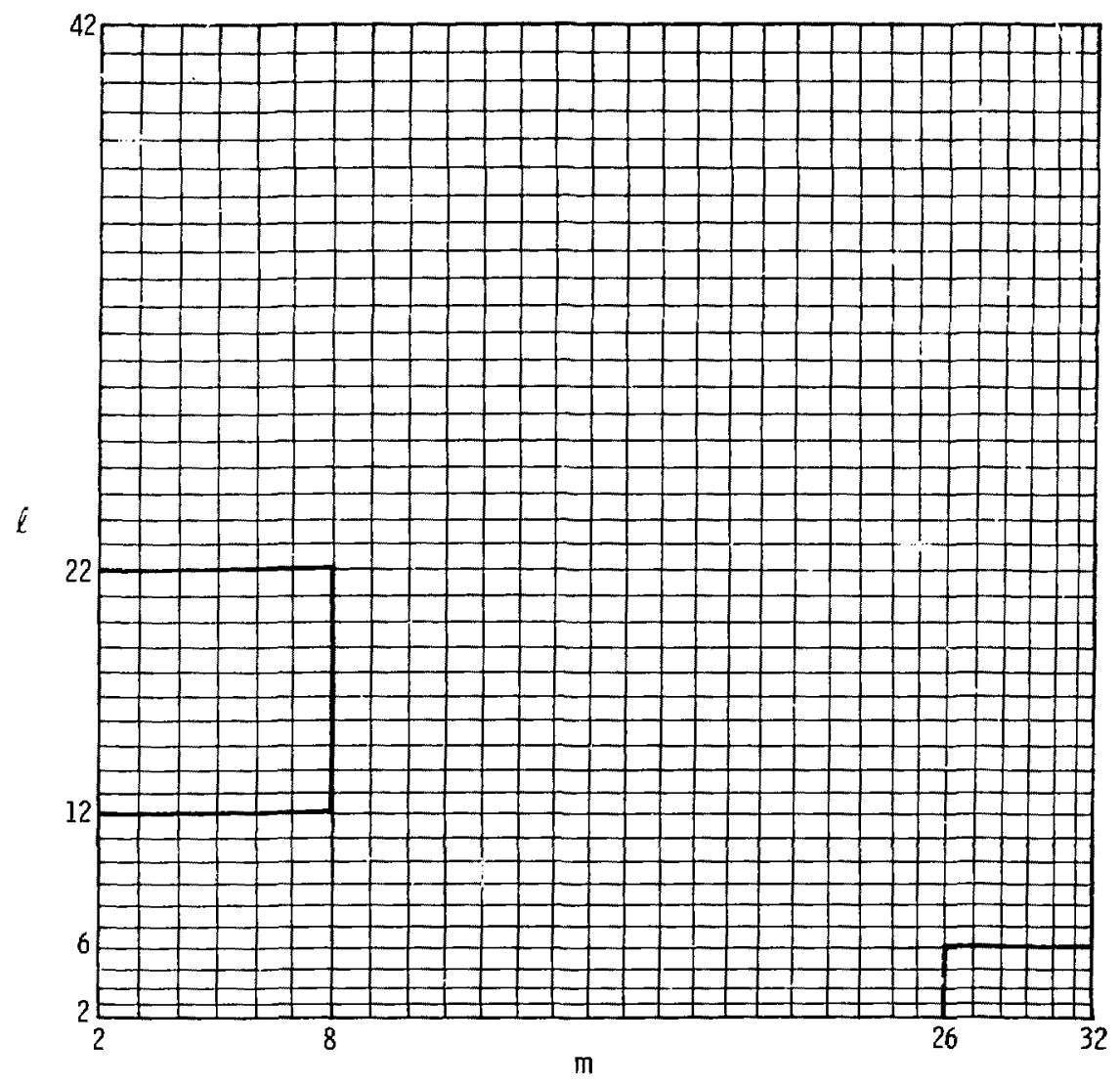

Figure 4. Location of Surfaces on the Honuniform Mesh for Sample Problem. 
upper surface is a surface whose normal vector pointing into the region of solution is in the $-r$ direction. A lower surface has its normal vector pointing in the $+r$ direction. Similarly, the normal vector for a right surface is in the $-z$ direction and for a left surface in the $+z$ direction.) All surfaces must be described to GePoIs via the array $\operatorname{IDS}(I, J, K)$ which is defined in the calling program. IDS $(I, J, K)$ is a three dimensional array. The I index runs from 1 to 4 and identifies the surface as either 1) an upper surface 2) a lower surface 3) a right surface or 4) $\exists$ left surface. The J index identifies which surface of type I the particular surface is (for example IDS $(2,3, K$ ) is the third lower surface). Each surface has five pieces of information stored in IDS which describe the surface. The $K$ index varies from $J$. to 5 . If $K$ equals: 1) $\operatorname{IDS}(I, J, 1)$ contains the grid line on which the $J^{\text {th }}$ surface of the $I^{\text {th }}$ type falls 2) IDS $(I, J, 2)$ contains the lower extent of the surface in terms of grid lines 3) $I D S(I, J, 3)$ contains the upper extent of the surface in terms of grid lines. If a boundary surface is to be a symmetry boundary then $\operatorname{IDS}(I, J, 4)=-1$ otherwise $\operatorname{IDS}(I, J, 4)=0 . \operatorname{IDS}(I, J, 5)$ contains a surface identifying number. Each surface has a unique number associated with it. The surfaces are labeled $1,2, \ldots$ Noss with ali upper surfaces numbered first, then lower surfaces, then rigit surfaces and finally left surfaces. Figure 5 shows the sample problem with surfaces appropriately numbered. A final requirement in 


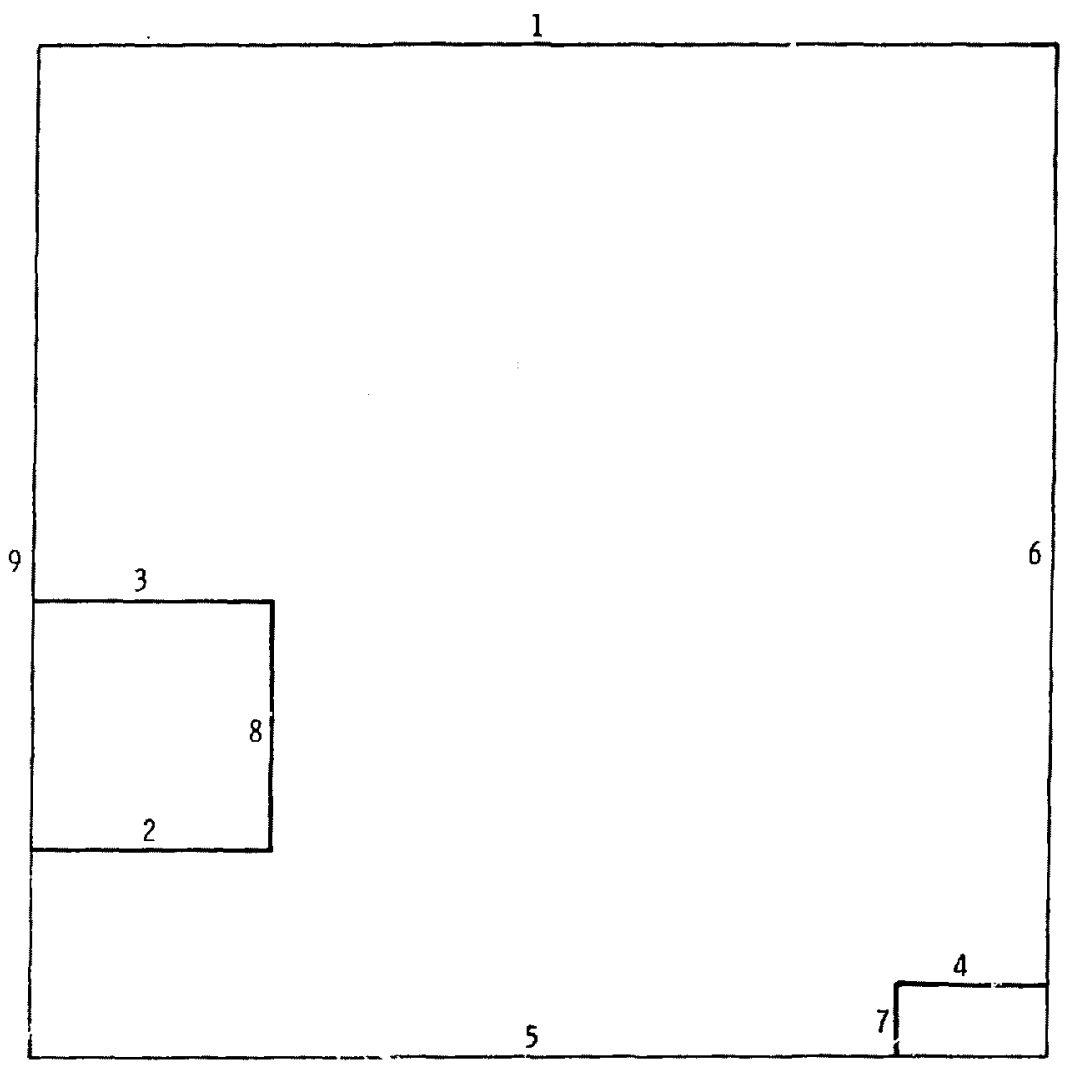

Pigure 5. Surface Idertification for Sample Problem. 
describing the surfaces is providing the array NOS(N). The array NOS(N) contains the number of each type of surface $\operatorname{NOS}(1)=2$ means that there are 2 upper surfaces. $N=2,3$ or 4 apply to lower, right and left surfaces respectively.

The perimeter boundary surfaces which surround the nisil region are described as cither Dirichlet or homogeneous Neumann boundaries by defining $I B C(N)$ to be 1 or 2 . $N$ again specifies the boundary surface as upper, lower, right or left for $N=1,2,3$, or 4 respectively. If IBC(N) equals 1 then the surface is a Dirichlet boundary (and PHI(L,M) must be specified on this boundary). If $\operatorname{IBC}(N)$ equals 2 then the surface is a homogeneous Neumann boundary and $\frac{\partial \phi}{\partial n}=0$ will be enforced there.

Subroutire GePOIS must be called once as a dummy call to set all constants which are used subsequently. This dumny call is accomplished by calling GEPOIS with ISE' $=1$. No potential computation occurs during this call to GEPOIS. Subsequent calls to GEPOIS should be made with ISET $\neq 1$. If any of the following inputs to GEPOIS change IMX, CONV, R, 2, IDS, NOS, NOSS, IBC another dummy call with ISET $=1$ must be made. Of course changes in PHI or RHOEZ are allowed between subsequent calls to GEPOIS without an intervening dummy call. In addition IEF inay change frm 1 to 0 or back, but only 
if IEF was set to 1 during the last duniry call to cepors, otherwise IEF indst remain 0 until changed by another dummy call.

Appendix I summarizes each of the above parancters with their required dimensioning if any. Appenuix II gives the aplopriate input used to solve the sample problem of Ficure 3. The equipotential plot which results from the solution of the sample problem is siown in Figure 6 . as a final example of the code flexibility figure 7 shows an eciuipotential plot for a complicated system. This problem was solvert with IEF $=0$ because of the surfaces which do not lie on grid lines. Computing the proper normal E field component on slanted surfaces is beyond the scope of this code because of the difficulty in making such a routine general enough to handle all possible cases. Normal electric fields have been computed on slantea surfaces for specific problems in the past using this routine witi ninot modifications ${ }^{5}$. When IEF $=0$ the information in the in the IDS and NOS arrays is not used. Poisson's equation is solved for the exterjor boundary conditions given by the IBC array. Any grid points which have INELP' equal to 1 will be held at the value of potential specified in the PHI array before the call to GePoIS. In Figure 7, a piece aise linear approximation to a quarter circle (which resultis in a hemisphere when revolved about the $r$ axis) is held at $V$ volts. A slanted surface structure is held 


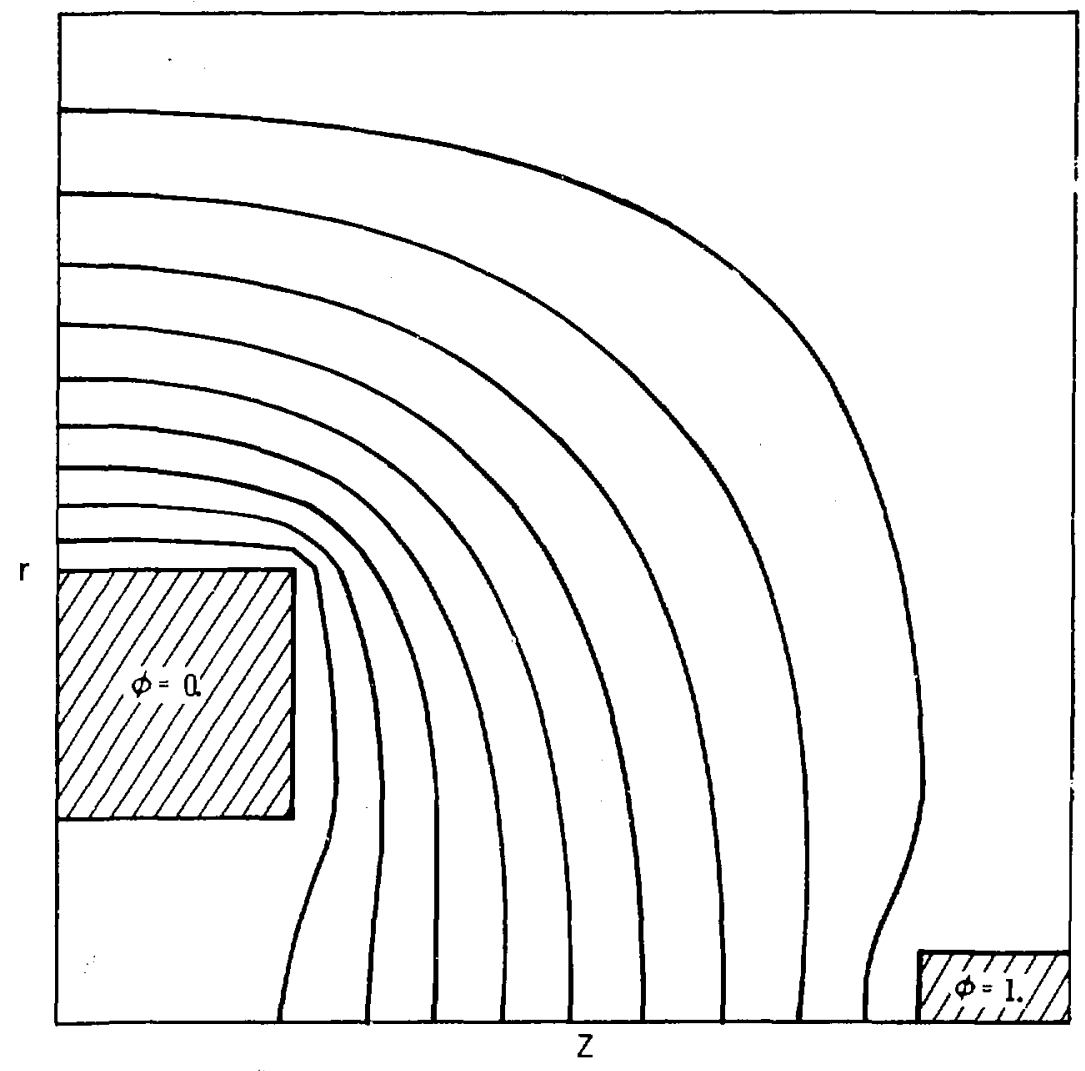

Figure 6. Equipotentlal Plot for Sample Problem. 


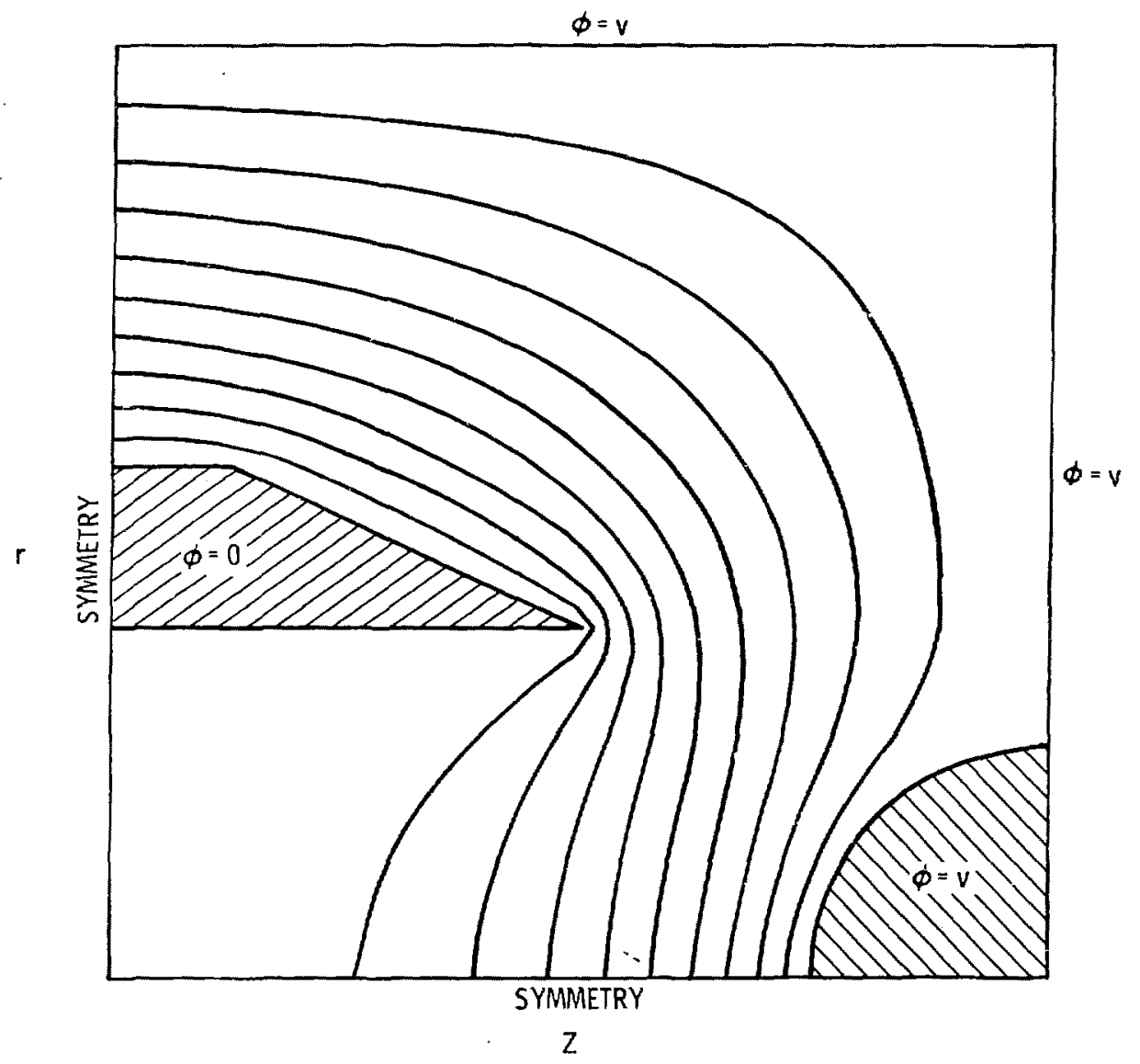

Figure 7. Equipotent1al Plot for More Complicated Geometry. 
at o volts. Equipotential lines which result from the solution of this problem are shown. This configuration could represent a hemispherical target mounted on the anode in a tapered cathode diode. 
Appendix I. Summary of Input Parameters and Dimensioning . A. Dimensioning

In the calling irogram the user must dimension the following variables

$R(N R), \operatorname{DUMERC}(3, N R)$, $\operatorname{DUMDR}(N R)$ $\mathrm{Z}(\mathrm{NZ}), \operatorname{DUMEZC}(3, \mathrm{NZ}), \operatorname{DUMDZ}(\mathrm{NZ})$,

DUMABC $(6$, NMAX), DUMAOP (3,NMAX)

INELPT(NR,NZ), PHI (NR,NZ), RHOEZ (NR,NZ),

$E R(N R, N Z)$

where NMAX is the larger of NR or NZ and NR and NZ are specified below. (Note: ER and RHOEZ must be dimensioned even if $\mathrm{E}$ field computations are not desired; IEF $=0$ )

B. Calling Parameters

\begin{tabular}{|c|c|c|}
\hline ISET & $=0$ & $\begin{array}{l}\text { This is a dummy call to } \\
\text { GEPOIs used to set constants } \\
\text { Not a dummy call - Compute } \phi\end{array}$ \\
\hline IEF & $\begin{array}{l}=1 \\
=0\end{array}$ & $\begin{array}{l}\text { Conpute E fields too } \\
\text { Don't compute E Fields }\end{array}$ \\
\hline $\operatorname{Im} x$ & & $\begin{array}{l}\text { Number of iterations before } \\
\text { printing convergence failure } \\
\text { message }\end{array}$ \\
\hline $\operatorname{conv}$ & & $\begin{array}{l}\text { Convergence criterion as } \\
\text { defined in equation ( } 17 \text { ) }\end{array}$ \\
\hline NR & & Number of $r$ grid lines plus 2 \\
\hline NZ & & Number of $z$ grid lines plus 2 \\
\hline
\end{tabular}




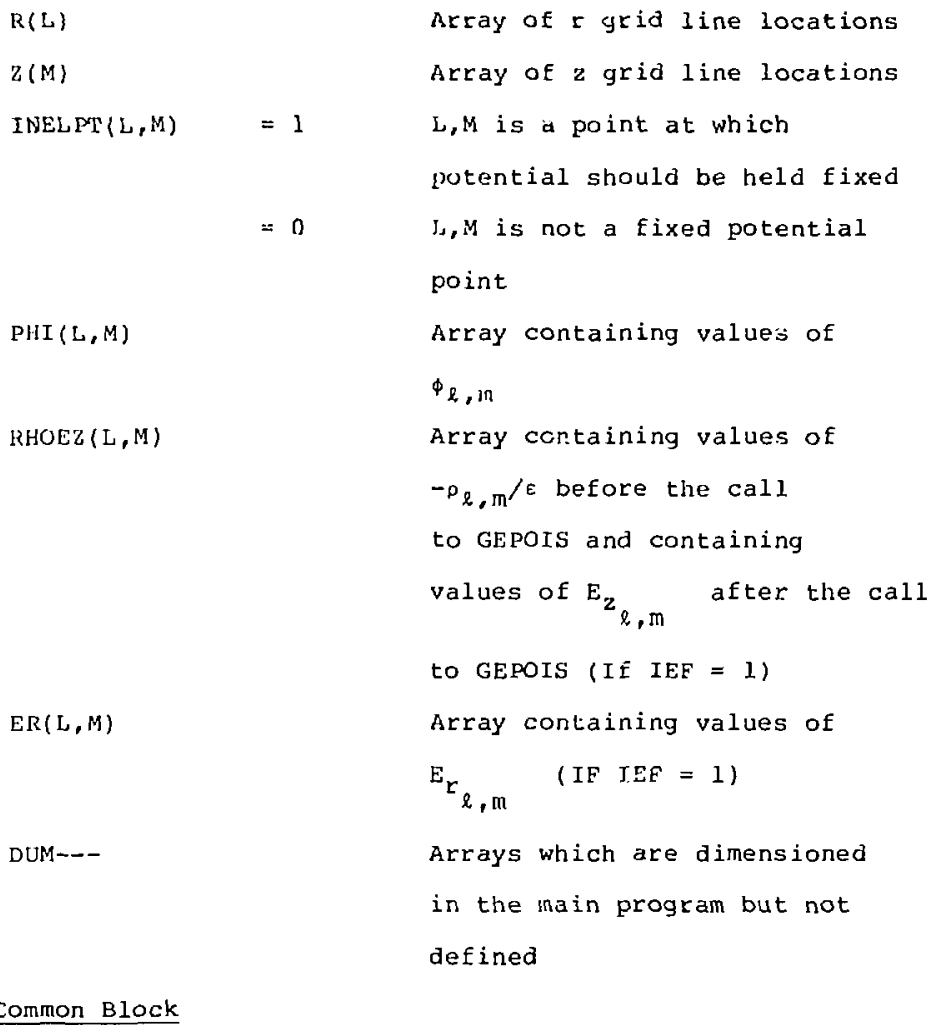

\section{c. Common Block}

The calling program must contain the common block SURF COMMON/SURF/IDS $(4,4,5), \operatorname{NOS}(4), \operatorname{NOSS}, \operatorname{IBC}(4)$

where IDS $(I, J, K)$ describes the surfaces in the problem:

$\begin{aligned} I & =1 & & \text { upper surface } \\ & =2 & & \text { lower surface } \\ & =3 & & \text { right surface } \\ & =4 & & \text { left surface }\end{aligned}$




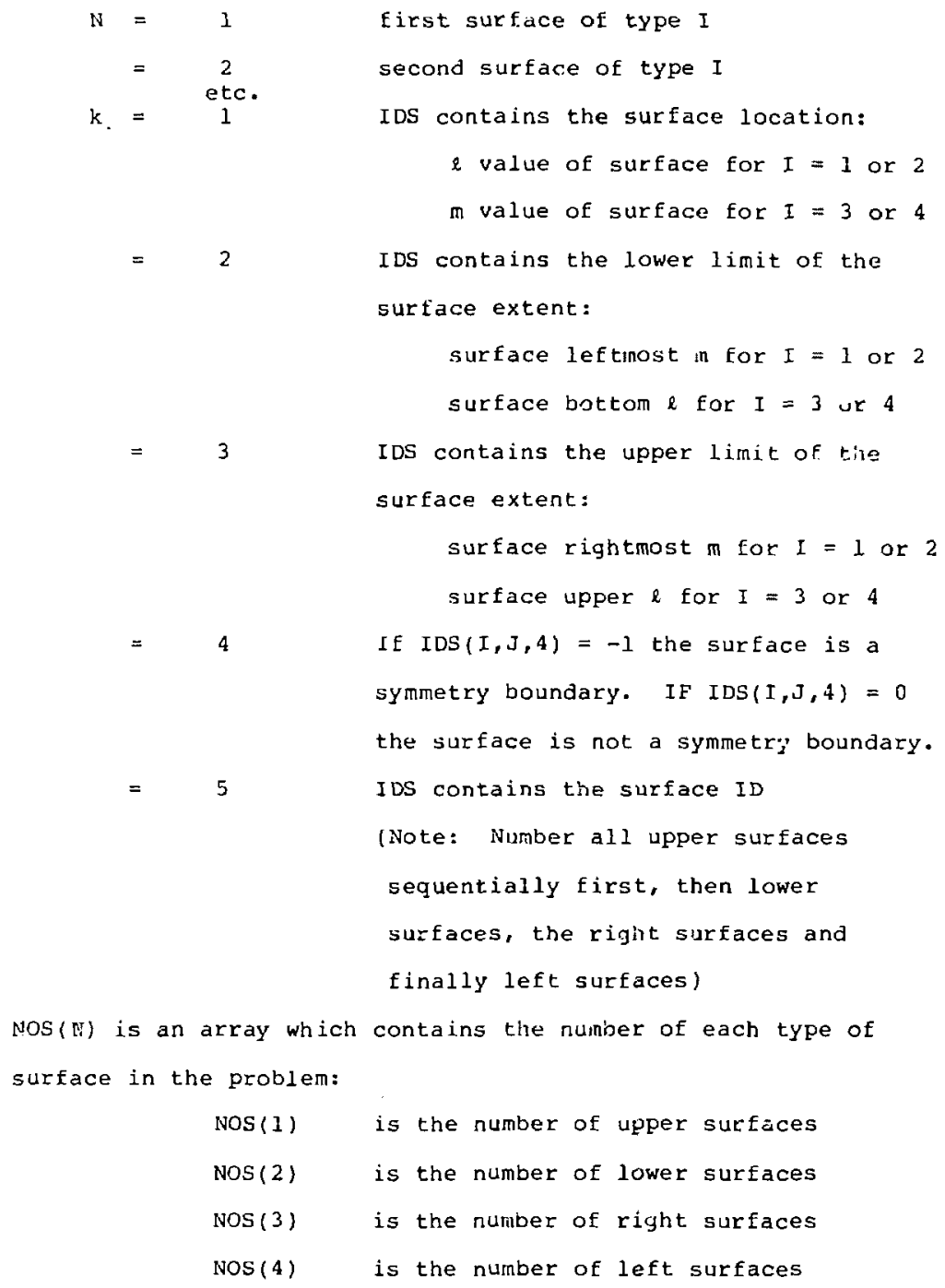


NOSS is the total number of surfaces

$$
\text { Noss }=\sum_{N=1}^{4} \operatorname{Nos}(N)
$$

IBC(N) is an array which describes the perimeter boundary surfaces as either Dirichlet or homogeneous Neumann

$$
\begin{aligned}
\operatorname{IBC}(N) & =1 & & \text { Dirichlet } \\
& =2 & & \text { Homogeneous Neumann }
\end{aligned}
$$

where $\mathrm{N}=1,2,3$ or 4 stands for upper, lower, $r$ ight and left boundaries respectively. 
Appendix II. Input for sample problem.

The input required for the sample problem of Figure 3 is given here

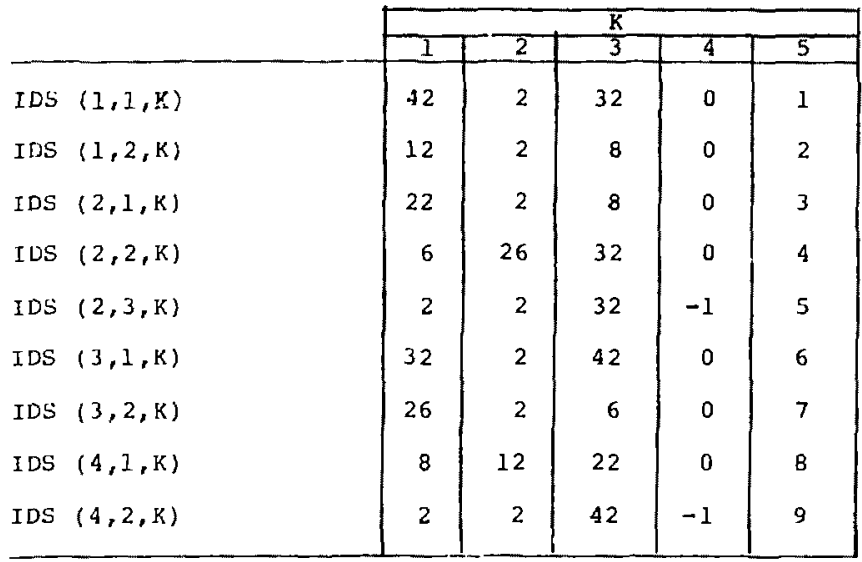

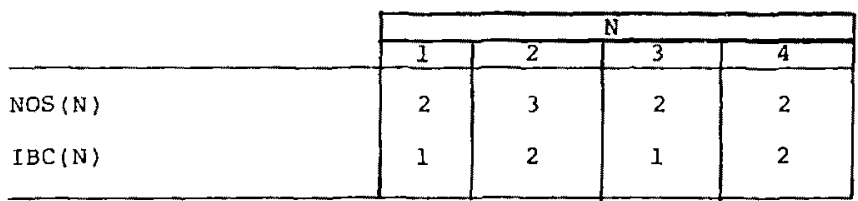

$$
\begin{aligned}
& \text { NOSS }=9 \\
& \text { IMX }=3000 \\
& \text { CONV }=10^{-15} \\
& \text { NR }=43 \\
& N Z=33 \\
& R(L)=\left(\frac{L-2}{40}\right)^{1.15} \\
& Z(M)=1 .-\left(\frac{32-M}{30}\right)^{1.20}
\end{aligned}
$$


INELPR $(L, M)=0$ for all $L$ and $M$ except

$$
\begin{aligned}
& \text { INELPT }(L, M)=1 \\
& \text { when }
\end{aligned}\left\{\begin{array}{l}
22<I, \angle 22 \text { and } \\
2 \leq M \leq B \\
\text { or } \\
2 \leq L \leq 6 \text { and } \\
26 \leq M \leq 32
\end{array}\right.
$$

$\operatorname{PHI}(L, M)=0$. for all $L$ and $M$ except

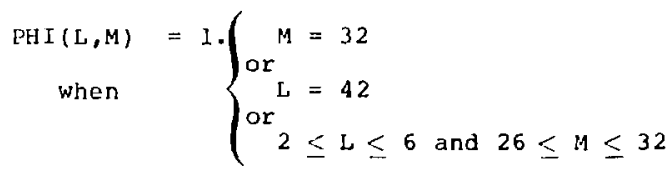

RHOEZ $(L, M)=0$. for aIl $L$ and $M$. 
Appendix III. Code Listing.

SUGRCUTINE GEDOIS IISET,IEF, IM X, COHV,NR,NZ,R, Z, INELPT, FHI, ER, PHOEZ 1, GOCDEF, TU4,EOC,EZC, OR, Z7)

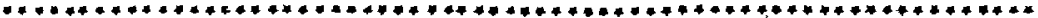

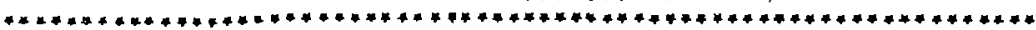

$+$

* ron THSEFtotTan

$+\bullet$

ZU BRUITINE DEPOIS, TORETHER HITH ITS COMFAUION ROUTINE

GE ISLU, CAMOUTES YHE ELECTFIC DOTEATIAL AND THE ? ANO

$Z$ PCMDCHENTS OF THE ELECTRIC FIELO JVED A SPECIFIEJ

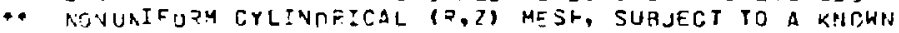

\# THAPGE DISTPIBIJTIOH AND OATHER GENE?AL 3OMHJAGY

* SOVIIT:ONC. ThE USEz -hCULE COHSUlt SANIIA PEPORT

* :U 49E 77-69?9FCF INFOPMATIJH ON THF USE JF THESE

* RMITINES. THIS CORE WAS HPITTEN ANO IS MAINTAINED gY

* J. F. JUIVTENZ, SAYLIA LABORATORIES, DIV. 4241

* AL TUJUEPJUE. N"A 97135 .

$+4$

.

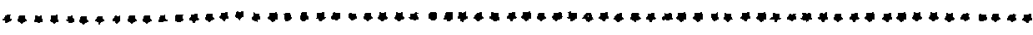

OI MFNSIOH ABCJEF $(6,1), E Q C(3,1), D(1), P F(1), E Z C(3,1), 21), 0 L 11$

$11, \operatorname{Tum}(3,1)$

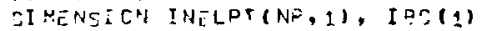

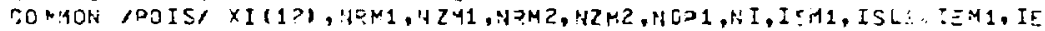

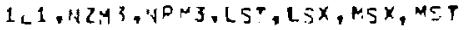

COMMON /SU2F, ISS $(4,4,5), 110 S(4)$, NOSS, IEC $(4)$

3I MENSIOU PH! (NP, 1), FEIND, 1), P HOEZ (NHA1)

SIMENSION LV(a), ML (6), YU (6), FV(E), MV $(6), L L(6), L U(6), I 1(6,2)$

1. $A A(5,3), B(5,3), G G(6,3), E E(E, 3), \operatorname{CC}(6,3,2)$

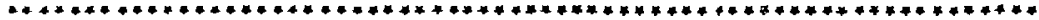

THE FIPST PASS THOJUSH GEPJIS COYDUTES ALL DEOUIPEE

COASTALTS ONES ANO STCEES THEM FEF SUBSEDUENT USE.

FOR THIS PEASON **A A DUYMY CALL TC GEFOIS IS REJUIPEO ***

BEFOPE THE FIPST POISSCR SOLVE.

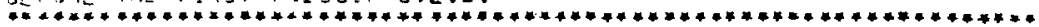

IF (ISET,NE.1) GO TS 3 月D

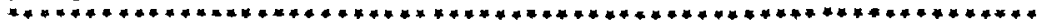

COOPLTE PEQUTREO INOICES

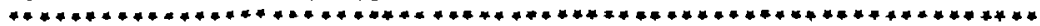

CO $30 \quad \mathrm{~J}=1.4$

IF (NOS (N) , G , 4.ANT. IEF,ED, 1) 10,20

1. PQINT 5RJ

STCD

20 COATINUF 


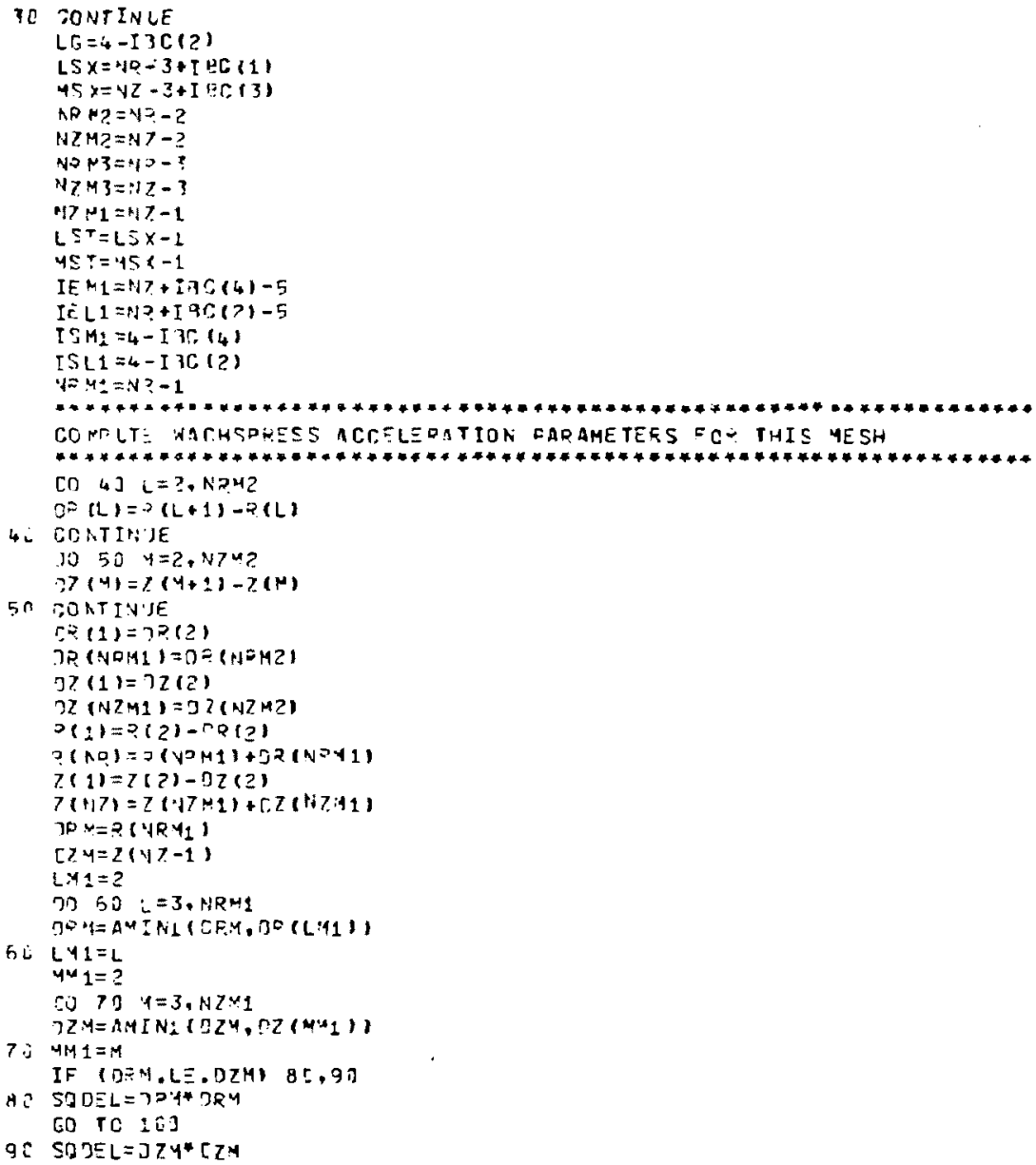


100 Conthise

ME $S H Y Z=(?(N Z-1)-Z(?)) / 0 Z 4+1$

HE SHME $=(2(N 2 M 1)-F \cdot(2)) / C O M+1$

YE SHMX $=M A X$ I (MISSHYO, MESHNZ)

$N C=12$

IF (MESH:HX.LT.10550) $\quad 2:=1:$

IF (MESHMX.L $\div 4377$ ) NO=1]

IF IMESHMX $L T \cdot 1813, N E=9$

IF (:1 $\Xi J H: 4 X, L T \cdot 751) \quad N \Omega=8$

IF (ME $\left.M H A X, L^{\top}, 312\right) \quad N C=$ ?

IF (RE;HYY.LT.1PQ) N]=E

IF (YEJH:\{K,LT, 54), $10=5$

IF (ME $3 H 4 X . L T .23) \quad \mathrm{Ng}=4$

IF $\left(4 E S H^{4} 4 X\right.$. LT.10) $Y 3=3$

IF (MESHYX.LT.5) NJ=?

OI $=3.141592654$

TI $C$ C $=P I I$ I

$\triangle P r_{3}=F I 02, Y \equiv S H M X$

HCP1 $=$ N D 1

No $M 1=N O-1$

-C OP $\left.=\operatorname{COS}\left(A^{\circ}\right)^{\circ}\right)$

Tr,DI= * TCON*TCON

TCON1= TAN(ADT)

TSON $1=1, A(T C O N 1 * T C O N 1)$

[C $11 E \quad H=1, N$ ?

$\mathrm{N}=4-1$

$F N=N$

FNI $191=-1041$

$\sum X=F N / 2 N O M 1$

$11.9 X Y(4)=T \operatorname{CON} /(\operatorname{TCON} 1 * * X * S O D \equiv L)$

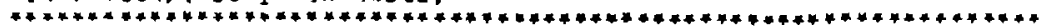

CDNOUTATIOR DF COEFFICIENTS IN ACI SOLUTION OF FINITE

[IFFERENCE ADPPOXIMATIOR TO POISSCNS EOUATION

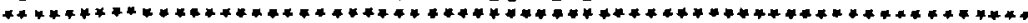

$L G=3$

CN $X=D Q(1) * 0 D(2) *\left(0^{2}(1)+D R(2)\right)$

$A Q \cap 9=F(1,2)=4, * 0 Q(1) / C H X$

$A B C J E F(2,2)=-4, *(D F(1)+C K(2)) / O N X$

$A P, D E F(3,2)=4,0=(2) / E N X$

12 a CONTIULE

Co 13: L=LC,LSX

$L M 1=L-1$

$T N=\left(\left[F(L)+D P\left(L M_{1}\right)\right)+D P(L) * g=\left(L H_{1}\right)\right.$

$A B C] E_{F}(1, L)=\left(2_{0}+D P(L M 1) / P(L)\right)+D R\left(L M_{1}\right) / D N$

$A R C D E F(2, L)=(D E(L) *(D=(L) /=(L)-2)-,D R(L N 1)+(D F(L M 1) / Q(L)+2.) / D N$

13] $\triangle B C D E=\{3, L 1=12 .-D F(L) / R(L I) * O R(L) / C N$

CC $14: \quad H=2, N 741$

$4 M 1=M-1$

$J N=\left(C Z(M)+07\left(M M_{1}\right)\right)+07(4) * D Z\left(* M_{1}\right)$

$A 3 C D E F(4,4)=2 .+0 Z(M M 1) / C N$

Q BCDEF $(5, M)=-2 . *(D Z(M)+C, Z(M M 1)) / O N$ 
140 ABCDEF $(6, H)=? \cdot \square 7(M) / D N$

IF IIEF. $E D .0)$ GO T? $37 \mathrm{r}$.

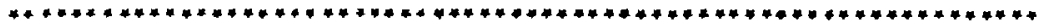

COHPLTATION OF COEFICIEKTS FOF DERIVATIVES JN A YDRIUNIFOFM

YESH, JSED IIT THE SOMOUTATION OF THE ELECTFIC FIELO FODH

THE FOTEMTIAL

$L S=2$

IF (F)? I.E.].) 150.163

$253 \quad L S=3$

16: EONTINLF

CO $170 \mathrm{~L}=L$ S.PJM 1

$\mathrm{LM} 1=\mathrm{L}-1$

SII $4=5.2(L)+D P(L) 11)$

ERC $(3, L)=-0 R(L M I) /(S U N * C O(L))$

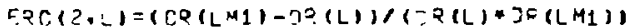

17 S $\equiv R C, 1:, L)=n=(L) /(5 U Y+n \in(L 41)$

$45=$ ?

IF $\quad 121 \geq 1.50 . \therefore 1, M S=3$

[D $140 \quad \mu=45,47 \because 1$

$141=M-1$

$S U: A=D Z(M)+D Z(M M I)$

$\equiv Z C(3,4)=-D Z(M+1) /(S U N+[Z(4))$

$E P C,(2, N)=(r Z(M M 1)-7 Z(M)),(\cap Z(M) * D Z(441))$

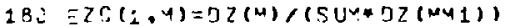

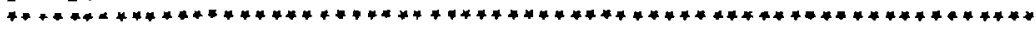

SUFFACE INFOOMATIOH COMOILED

IN $r X=1$

$A E F A=?$

CC $213 \mathrm{~J}=1,2$

NS $S=\sqrt{ } \mathrm{C}(\mathrm{J})$

$3021 \mathrm{~N} N S=1,155$

IF (IOS (J.NS.4).LT.O) GC TO 210

$A \equiv Q B=N I=F+1$

$L=I J S(J, N S, 1)$

LV $(N E ? 3)=L$

$M L(N E P, 3)=\operatorname{IDS}(J, N S, ?)$

YUU $\left(N E Q A^{2}\right)=\operatorname{IOS}(\mathrm{J}, \mathrm{NS} .3)$

FV $(N E F, 3)=R(L)$

IF $(\bar{R}(L), E Q .[.) \pm 9 \%, 200$

19? $A E F 3=N E O 3-1$

, 0 ro $21:$

COI CDNTINUE

I1 $(N=-3,1)=\mathrm{L}$

IF $(J . E Q .1)$ I 1 (NEDE. 1$)=L-2$

21. SONTINUE

HH $X=N E>B$

Go TO 240 


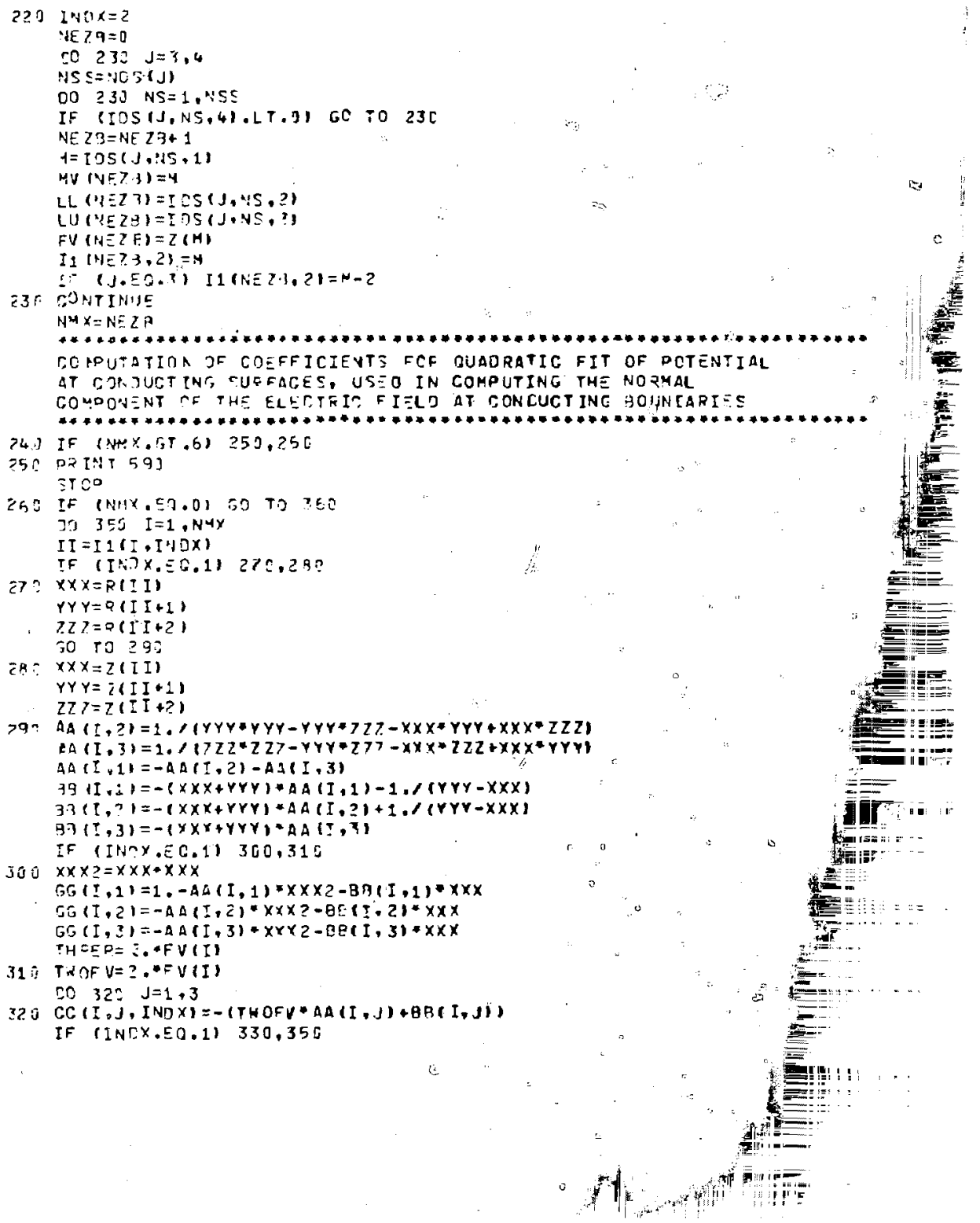


330 DO $340 \quad J=1,3$

$34 \Gamma E E(I, J)=T H D E O N A A(I, J)+?+B](I, J)+G G(I, J) / F V([1$

353 COP.TINLS

360 SONTINUE

IF (INDX.E0.1) 220.370

37 CONTINUE

ZETUPR

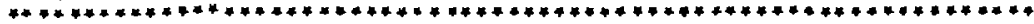

P.F. TURM FRTN CUHAY CALL TO GEDOIS

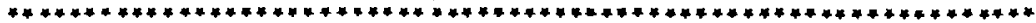

3RI CONTINUE

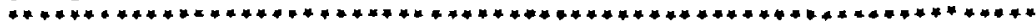

SU ISEJ LENT CALLS TO GEOOIS ENTER HEQE

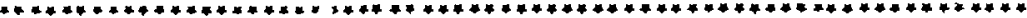

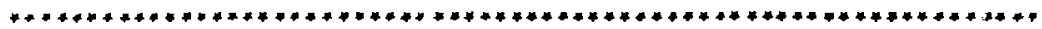

POTSSOH EQUATZON SOLVED BY ADI HITH WACHSPEESS ACCELERATION

IN TENSLV

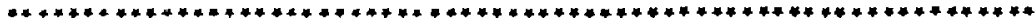

CALL GENSLV IIMX, CONV, DHDE?, DHI, NR, INELPT, ER, A AC OEE, DUM, OQ, OZI

IF (IEF.E).Q I FETUON

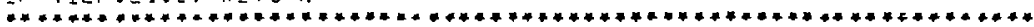

E FIELJS COMPIJTED OVER THE MESH

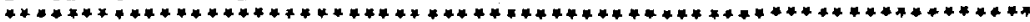

[5 $39 . \quad L=\mathrm{L} 5, \operatorname{HP} 41$

$L O_{1}=L+1$

$L M_{1}=L-1$

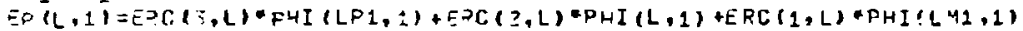

$E=(L, N Z)=E R C(3, L) * D_{4} I(L D 1, \cup Z)+E R C(2, L) * P H I(L, N Z B+E P C(1, L) * D H I(L i\{1$,

$1 \wedge Z$

CO $390 \quad M=4 S, N 7 M_{1}$

$E_{R}(L, Y)=E_{R} C(3, L) * P H I(L O 1, M)+E K C(2, L) * P H I(L, M)+E R C(1, L) * P H I(L Y 1, M)$

235 DHCEZ(L,M)=EZC $(3, M) * D_{H I}(L, M+1)+E Z C(2, M) * P H I(L, M)+E Z C(1, M) * O H I(L, M-$ 111

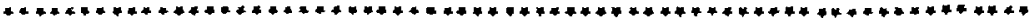

VOPYAL EFIELJ COMPJNENTS DOMPUTED ON CONDUCTING SURFACES

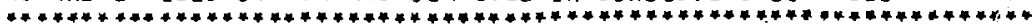

TO $1: 10 \quad I=1, N E ? ?$

$L E=\mathrm{L} V(\mathrm{i})$

$L L F=I I(I, 1)$

YHI:V $=M_{-}(I)$

YMA $A X=M, Y(I)$

DO $40.3 \quad M=M .4 I M, M H A X$

4CE $\equiv ?(L \equiv, Y)=C r,(I, 1,1) * I(L L P, Y)+C G(T, 2,1) * P H I(L L P+1, M)+C C(I, 3,1) * P H I$

$1(L L P+2, M)$

41 O CONTINUE

CO $430 \quad I=1, N=Z F$

$M E=M V(I)$

$M Y P=I 1(I, 2)$

LMI'U $=L L(I)$

L.YAX $=L U(I)$

SC 420 L=LYIN,LHAX 
420 ZHOE $Z(L, M E)=C, C(I, 1,2) * P H I(L, M H P I+C C(I, 2,2) * P H I(L, H M P+2)+C C(I, 3,2) *$ 1 OHI $(L, M H P+?)$

43.9 CONT INUE

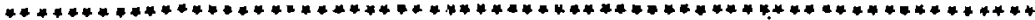

SETS NJRYAL COYPONENT OF E FIELD TO ZEPO ON SYMMETRY IJUNOARY

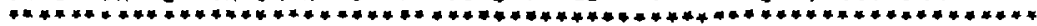

CO $450 \mathrm{~J}=1,4$

NS $S=N C S(J)$

J0 45 E NS $=1$, NSS

IF IIOS (J, HS, 4), GE. J) GO TO 450

IX $V=I O S(J, N S, 1)$

$I X L=I 0 \leq(\mathrm{J}, \mathrm{NS}, 2)$

$I X H=I 0 !(J, N S, 3)$

DO 44 ? IXX $=I \times L, I \times H$

IF $(J,-E, S) E R(I X V, I X X)=3$.

$44 \mathrm{CONTINUE}$

IF $(J . G E, ?)$ Q QHOEZ $(T \times X, I X V)=0$.

45 C SONTIHUE

If (LS.E. 3.3$) 450.433$

453 CO $473 \mathrm{~S}=45, N Z \mathrm{HZ}_{2}$

\& 7 C $R H C E Z(2, M)=E Z C(3, M) * D H I(2, M+1)+E Z C(2, M) * P H I(2, M)+E Z C(1, M) * P H I(Z, M-$ 111

480 JF I4S.E. $31490.5: 0$

490 CO $50 \hat{A} \quad L=L S, N F 42$

50 ? EP $(L, 2)=E R[(?, L) * P H I(L+1,2)+E R(2, L) * P H I(L, 2)+E R C(1, L) * P H I(L-1,2)$

510 CONTINUE.

If $(I 3 C,(4), E 3 . ?) \quad 529,54$ ?

52. $0053 i$ L $L=L, N E M$ :

530 RHCE.Z\{L, 2$\}=0$.

540 IF (IBC I 2). ER. 21550,570

$55.200560 \quad M=4 S, N 7 M 1$

$5625 \%(2, M)=3$.

570 RONTINUE

RE TIJP.!

5RO FOOMAT 133 MDEE THAN 4 OF DNE TYPE SUFFACE,

1 IA ALL SOMMON BLOOKS,, 214 AND REMOVE THIS TESTI

593 FO RYAT (33H DIMENSIONING IN GEPOIS TOO SMALL)

Ev [ 
SU 3RCUTINE GENSLY (IMX, CONV, G, FHI, AT, INELOT, PFT, ABCDEF, AOP, DR, DZ) (I ME ASI ON IMELPT (AT,1), PRT (NT,1), DP(1), CT(1)

CIMEASION ABCDFF $(6.1)$

OE MENS L OAT G(UT,1), OMI (NT, 1), AURP(3,1)

COMYON, $00 I S, X I\left(1 ? 1, N T N_{1}, N S M_{1}, N T M 2, N S M 2, N O P 1,: U I, I S M 1, I S L 1, I E H 1, I E\right.$

1L1, NSM , ITT Y3, LST, L $X X, M \subseteq X, M S T$

CONMON RSUOF, IDSC:14 $(4,4,5)$, NOSOUM $(4)$, NOSSOU, I3C $\{4\}$

N $\mathrm{N}=\mathrm{O}$

to $>T_{2} \quad \mathrm{NI}=:$ : INX

S!) $4 N=5$.

SI] $N=0$.

$N=N+2$

IF $(1900(N, N D P 1)$. ED.J) $\mathrm{H} i=$ :

ro $1: L=?, N T M$

10 A) $P(1, L)=D H I(L, I B C(4)+1)$

JO $14: M=$ LSM1,MSX

$\because 01=1+1$

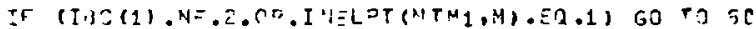

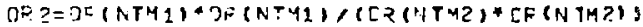

$[N T=A P: D E F(2, N T M 1) \rightarrow X I(T:)+A] C D E F\left(1, N T M_{1}\right) *(1,-D=2)$

$\triangle O P(2,1 T M 1)=-(A B G C E F(1, N T M 1) * D D 2+A A G D E F(3, N Y M 11) / C N D$

IF (M, $=0 . N \leq M \geq) 2 E, 30$

$20 \quad 4 S T=T,(N T H 1, H)-A Q C O E F(4, M) * 5 H I\left(N T N_{1}, N S H 2\right)-(A B C D E F(5, M)+X I(N))+P H I(N$

$1 T M \pm, 1)-A 3$ C NE.F $(6, M) * A \cap D(1, N T M 1)$

जo TO 40

3: CONTINIE

4S $T=-A, C$ COEF $(4, M)$ * PHI $\left(N T N_{1}, M P 1\right)-$ (AEC DEF $\left.(5, M)+X I(N)\right) * P H I(N T M 1, M)-A E C$

I ?EF $(6, Y)+A O P\left(1, N T M_{1}\right)+C(H T M 1, Y)$

4 C CONT INUE

$A D O(I . N T M 1)=H S T / D N T$

ro TO 50

50 SONTINIJE

$\triangle O P(2, N T M 1)=?$.

$A O P(3,2 T Y 1)=$ PHI $\left(N T M_{1}, N\right)$

6: CONTINIJE

$I X F I=N T M 1$

CO $12 \mathrm{~J} \quad \mathrm{~L}=1, I \equiv L 1$

I $X=N T M I-L$

IF IINELOT $(I X, M), E O .1) 70,0.1$

$70 \quad A O P(2, I X)=0$.

$A O P(3, I X)=P H[(I X, M)$

GO TO 129

BI CONTINLE

$[N=A B C J F F(1, I X)+A C O(2, I X 31)+A A C D E F(2, I X)-X I(N)$

IF $(M . E 0, N S M 1) 90,100$

98. HST=G(IX,M)-ABCDEF $(4, M) * P H \perp(I X, N S M 2)-(A B C D E F(5, M)+X I(N)) * P H I(I X, M)$

$1-A \cap C D E F(6,4) * A C P(1, I X)$

GO TO 110

100 COATINUE

$H S I=G(I X, 1)-A G C D E F(4, M)=P H I(I X, M P I)-(A B G D E F(5, M)+X I(N))=P H I(I X, M)-$ $1 \triangle B C O E F(6, M) \times A O P(1, I X)$ 
IIn CORTINIJE

$\triangle O D(2,[x)=-A$ SCOEF $(3, I X) / D H$

$A O D(3, E X)=(H S T-A S C D E F(1, I X)+A O P(3, I X P 1)) / D N$

12. $โ X C_{1}=I X$

$A O F(1,2)=0 H I(2,4)$

IF (IR, (?) .EQ.2. AR, INELDT $(2, M), \leq 0,0)$ PHI $(2, H)=(A O P(2,2) * A O P(3,3)$.

$\triangle A D P(3,2))(1,-A O P(2,2)+A O P(2,3))$

CJ $13 B \quad L=2, L S T$

$L P:=L+1$

$A D P(1, i F 1)=D H I(L P 1, M)$

IF $(I N E L O T(L O 1, M)$. EJ.C) $P H I(L P 1, M)=A O P(2, L F I)$ "OHI $(L, Y)+A O P(S, L P 1)$

$1.3^{\circ}$ SODHTINJ

14: COUTIRLE

in $150 \quad y=2, N S 4$

25J $A D P(1, Y)=P H I(I A C(2)+1, M)$

CO $20 \mathrm{~d} L=I S L 1, L S X$

$L P L=L+1$

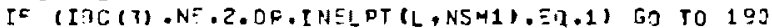

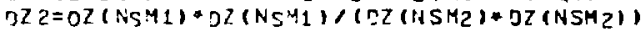

CN $C=A Q(0 E F(5, N S H 1)-X I(H)+A 9 C D E F(G, N S M I) *(2,-D Z Z)$

$\triangle D D: Z, V S M 1)=-\left(A D L D E F\left(4, N S N_{1}\right)=022+A 3 C D E F(6, N S M 1)\right) / D N D$

IF $(L, \equiv 0.2 \mathrm{TH} 1) 16 \mathrm{C} .17 \mathrm{~J}$

$15 C . \triangle 5 J=C Z L+N S H 1)-A 3 C D E F(1, L)+D H I(N T M 2+N S M 1)-(A 3 C D E F(2, L)+X I(N)) * P H I(L$

$1 . N 541)-A 5 C R E F(3, L)=\triangle O P(1, N S M 1)$

GO TO 180

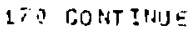

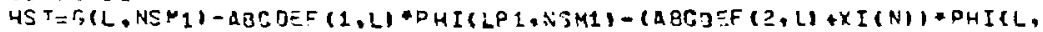

1 NS M:1-A GC CEF $(J, L) * A D P(1, N S \% 1)$

IRO CONT IHIJE

AOD (3, HISMI) = HST/ONJ

IO TO $2[0]$

19 SODTIRUE

$A g \square(2, A S 41)=]$.

$A O=\{3, \mid S 41)=D H I(L, N S M 1)$

20: CONTINUE

IXPI $=N S H I$

[0 $\geq 60 \quad M=1, I, M:$

$I X=V S M 1-Y$

IF (INELOT (L,IX) E EG.1) $210,22 C$

$210 A D D(2, I x)=0$.

$\triangle O P(3, I X)=P H I(L, I X)$

60 TO $? 60$

25: COHTIMLE

$J N=A 9 C J E F(4, I X) * A O P\left(2, I X D_{1}\right)+\operatorname{ARCOEF}(5, I X)-X I(N)$

IF IL.ED.NTHLI $230,24 \mathrm{~J}$

$23 \pi H S T=G(L, I X)-A 9 C O E F(1, L) * D H I(N T M 2, I X)-(\triangle B C D E F(2, L)+X I(N)) * P H I(L, I X)$

$1-A$ SC JEF $(3, L)+A C P(1, I \times)$

GO TO 250 


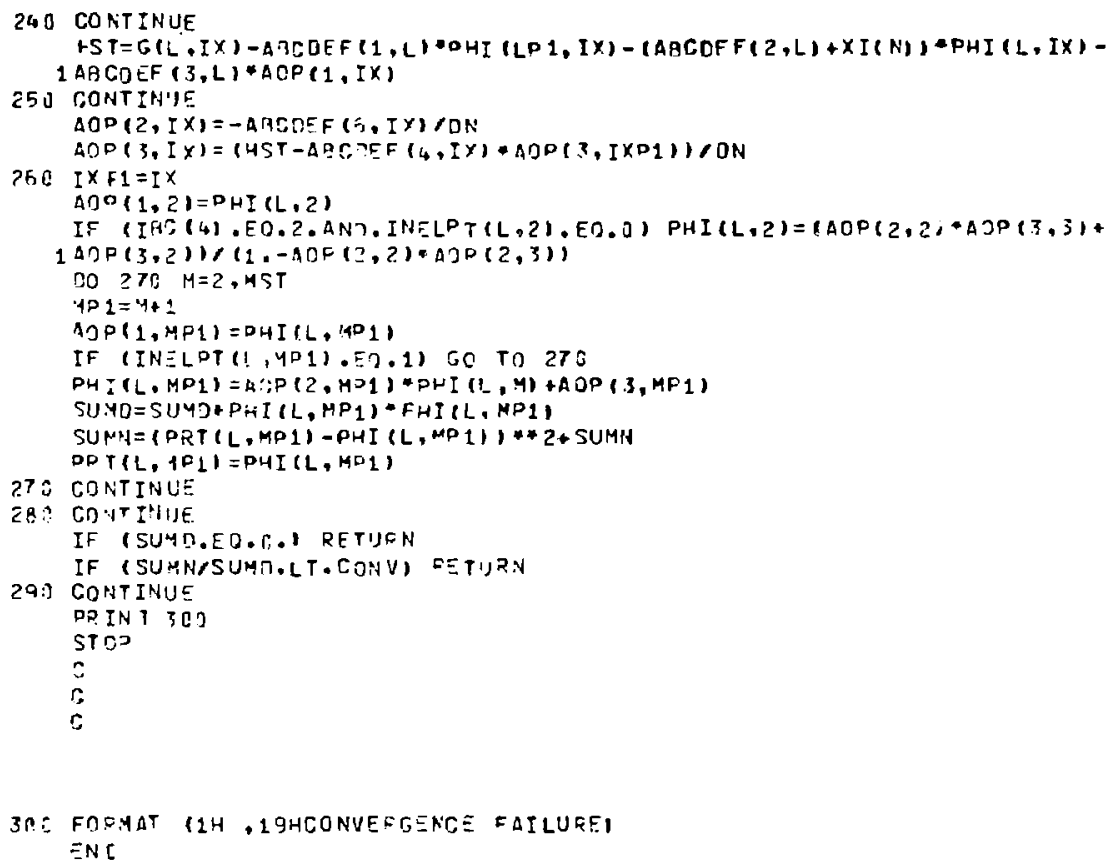




\section{Acknowledgments}

The authors would like to thank D. B. Seidel for Inaking several useful comments concerning the description of this code. Many useful discussions with $J$. W. Poukey are also acknowledged. 


\section{Refercences:}

1. J. W. Poukey, J. R. Freeman, and G. Yonas, J. Vac. Sci. Technol, 10,954 (1973).

2. S. Miller and z. Zinamon, Phys. Rev. Lett. 36, $130\}(1976)$.

3. J. '? Quintenz and J. W. Poukey, J. Appl. Phys. 48, $2287(1977)$.

4. L. Lee, Shyke A. Goldstein, ant D. J. Johnson, Bull. Am. Phys, Soc. 22, 1062 (1977).

5. J. P. Quintenz, J. Appl. Phys. 49, 4377 (1978).

6. E. Kalnay De Rivas, J. Comp. Phys. 10, 202 (1972).

7. J. R. Freeman and S. L. Thompson, J. Comp. Phys. 25, $332(1977)$.

8. A. R. Mitchell, Computational Methods in Partial Differential Equations, (Wiley, London, 1969). 